\title{
Peel Off Gel Mask Containing Green Tea Leaf Extract (Camellia Sinesis L) with Antioxidant Activity
}

\section{Chaerunisaa, A. Y.*, Khuzaimah, Z., Surachman, E.}

Faculty of Pharmacy, Padjadjaran University, Jatinangor, Jl. Raya Jatinangor Km 21.5 Sumedang, Indonesia

Received: 2 Jan 2021, Revised: 12 Feb 2021, Accepted: 23 Feb 2021, Published: 27 Feb 2021

\begin{abstract}
Peel off mask has been very popular and preferred due to its ease in application. Gel base has been preferred for its cold and moist sensation during application. When herbal ingredients such as extract is introduced into gel formulation, the stability then will become an issue. The aim of the study was to formulate the peel-off mask gels containing green tea leaves extract (Camellia sinensis L.) which effective, stable, and safe to be used. The antioxidant study was conducted by using Diphenylhydrazylpicryl (DPPH) method. The peel-off mask gel formula were Hidroxypropyl Methylcelulosa (HPMC) as gel base at $0.5 \%$ concentration and plasticizer Polyvinyl Alcohol (PVA) at concentration of $12 \%$. Evaluation of peel-off mask gel included observation on $\mathrm{pH}$, viscosity, dispersing power, and drying time during the 90 days of storage at room temperature. The IC50 values of the green tea (Camellia sinensis L.) extract was $5.511 \mathrm{ppm}$. The concentration of green tea leaves extract in the preparation were 1x IC50 (F1); 2x IC50 (F2) and 3x IC50 (F3). The result showed that all preparations were stable in the aspect of consistency, color, and odor. Viscosity, drying time and dispersing power remained unchanged after 90 days of storage. The $\mathrm{pH}$ value changed, but still in the range of acceptable $\mathrm{pH}$ of topical preparations. The results of antioxidant activity study showed that formula F3 (peel-off mask gels with $3 \mathrm{x}$ IC50 of green tea extracts) had the highest antioxidant activity.
\end{abstract}

Keywords: antioxidant, Camellia sinensis L., peel off gel masks, green tea

\section{Introduction}

Aging skin can be inhibited by using cosmetics that contain antioxidants. Antioxidants can reduce free radicals to be less reactive molecules, thus it can avoid and reduce oxidative damage. The use of antioxidants in anti-aging skin care is essential to prevent further skin damage1.

Antioxidants are grouped into two categories based on the source, which is an antioxidant that is naturally and synthetically derived 2 . The concerns about possible side effects that are not known from synthetic antioxidants cause natural antioxidant potential alternatives to be developed2. One of the potent plant as a powerful antioxidant is green tea leaves (Camellia sinensis L.). Polyphenol compounds are very important compounds in tea, especially in catechins class. The antioxidant activity of tea is related to the presence of catechins. Epigallocatechin gallate (EGCG) and epicatechin gallate (ECG) are types of major catechins in green tea. This compound has a 
strong activity to prevent free radicals such as peroxynitrite, superoxide, hydrogen peroxide 3.

With its high antioxidant content, green tea leaves can be used as one of the raw materials of cosmetic preparation. The selected cosmetic preparation is dosage of gel peel-off masks. Peel-off gel mask is a mask that is a practical one, because after the mask is dry, it can be immediately removed without the need to rinse4. The benefits of gel mask peel-off can remove impurities and dead skin cells to keep skin clean and fresh. This mask can also restore the freshness and softness of the skin, even with regular use it can reduce slight wrinkles on the skin5,6.

Based on the background, it is necessary to study the formulation of green tea leaves antioxidant extracts in gel peel-off mask (Camellia sinensis L.). The antioxidant activity of green tea will be measured before and after preparation is made into a mask. The stability of the preparation which includes physical and microbiological stability will also be observed within 90 days of storage.

\section{Materials and Methods}

\subsection{Instrument}

Instrument used included Digital scales (Mettler Toledo), water bath (Memmert), parchment paper, spatula, evaporating basin, stir bar, a mechanical stirrer, a $\mathrm{pH}$ meter (Hanna), Rion Viscometer, incubator (Sakura, IF-4), UV spectrometer (Specord 200 ), and glassware commonly used in Pharmaceutics, Microbiology, Phytochemistry and Natural Products Laboratory.

\subsection{Plant material}

Dried Green tea leaves (Camellia sinensis L.) were obtained from Plantation Manoko, Lembang, Indonesia and determinated in the Department of Biology Faculty of Mathematics and natural Science, Padjadjaran University.

\subsection{Chemical Material}

Diphenylhydrazylpicryl, Tri aethanol amine (PT.Quadrant), Glycerin (PT. Brataco), Eutanol G (PT. BASF), 10\% ammonia, chloroform, $2 \mathrm{~N} \mathrm{HCl,} \mathrm{Mayer} \mathrm{reagent,}$ Dragendorff reagent, Lieberman-Burchard reagent, Nessler reagent, distilled water, $\mathrm{FeCl} 3$ $\%, 1 \%$ gelatin solution has been used as recieved. $\mathrm{Mg}$ powder, ether, methanol, vanillin $10 \%$ solution, concentrated $\mathrm{H} 2 \mathrm{SO} 45 \%$ $\mathrm{KOH}, \alpha$-naphthol solution of $5 \%, 1 \%$ Ninhydrin solution, vitamin C, Mueller Hinton Agar (MHA), Sabouraud Dextrose Agar (SDA), Gelatin (PT. Brataco), nipagin (PT. Quadrant), Nipasol (PT. Brataco), Carbopol 940 (PT. Brataco), triethanolamine (PT. Quadrant), polyvinyl alcohol (PT. Brataco), HPMC (PT. Brataco), Propilenglikol (PT. Brataco) and distilled water were used as received.

\subsection{Experimental Methods}

\section{Extraction of Simplisia}

$2 \mathrm{~kg}$ of dried green tea leaves powder were macerated by using $96 \%$ ethanol for 3x24 hours at room temperature. The ethanol extract was then evaporated using a rotary evaporator under vacuum pressure at a temperature of approximately $35^{\circ} \mathrm{C}-40^{\circ} \mathrm{C}$ and kept at $4 \mathrm{oC}$ until used. Examination on parameters of the green tea leaves extract included water content, water and ethanol soluble extract content.

\section{Phytochemical screening}

Phytochemical screening was conducted to determine the secondary metabolite content of alkaloids, tannins, polyphenols, flavonoids, steroids, triterpenoids, quinones, saponins, monoterpenoid, and sesquierpenoid in simplisia drugs and ethanol extracts.

\section{Antioxidant Activity}

Investigation on antioxidant activity of the extract was conducted by using DPPH reagent and measured with UV-Visible spectrophotometric method. A total of $1 \mathrm{~mL}$ DPPH solution was added into a solution of 
sample at particular concentration. Vitamin C was used as a standard at concentration of 4, 2, 1 and $0.5 \mathrm{ppm}$. The absorbance of each sample were measured at a maximum wavelength of $\mathrm{DPPH}$ which is $517 \mathrm{~nm}$. Percentage of inhibition was calculated as follow:

$\%$ inhibition $=[1-($ A test $/ \mathrm{A}$ control $)] \times 100 \%$

In which:

A test $=$ average absorption of DPPH solution in the sample

A control $=$ Absorption of DPPH solution in ethanol

$\%$ inhibition $=$ Percentage inhibition of free radical

Optimation of Base for peel off gel mask

Table 1. The Base Formula of Gel Masks

\begin{tabular}{llll} 
Material & \multicolumn{4}{l}{ Formula } \\
\hline & F01 & F02 & F03 \\
\hline PVA (\%) & 12 & 12 & 12 \\
HPMC (\%) & 0,5 & 0,5 & 0,5 \\
Gliserin (\%) & 12 & - & 12 \\
PPG (\%) & - & 10 & 10 \\
TEA (\%) & 2 & 2 & 2 \\
Nipagin (\%) & 0,2 & 0,2 & 0,2 \\
Nipasol (\%) & 0,05 & 0,05 & 0,05 \\
Aquadest & \multicolumn{4}{l}{ Ad 100Ad 100Ad 100 }
\end{tabular}

F01 = Formula with humectant glycerin

$\mathrm{F} 02=$ Formula with humectants propilenglikol

F03 = Formula with humectant glycerin and propilenglikol

The PVA was dispersed in hot water (mixt. 1), HPMC was dispersed in hot water (mixt. 2), nipagin and nipasol were dissolved in ethanol (mixt. 3). Mixt. 2 and 3 was mixed, stirred and was added to a mixt. 1 and stirred by using a mechanical stirrer. Triatanolamin was added to form a clear mass gel. Next, then glycerine (F01), or propilenglikol (F02) or glycerin and propilenglikol (F03) was added and mixed vigorously until the gel become clear and homogeneous. The organoleptic investigation, $\mathrm{pH}$, viscosity, dispersion power and drying time were examined for 14 days of investigation.

\section{Formulation of Peel Off Gel Mask with Green Tea Leaves Extract}

Gel mask were formulated using the optimized gel using different humectant (F01, F02 and F03). To the optimum formula (F02), green tea leaves extract were added as much as 1, 3, and 5 times of the IC50 value. Extract were dissolved into ethanol and added to the gels, then stirred until homogeneous. Peel-off gel mask were prepared as follows: gel mask without green tea leaves extract as standar base of gel mask (F0): gel mask with tea leaves extract containing 1 x IC50 (F1): 3 x IC50 (F2) and $5 \times$ IC50 of green tea extracts (F3).

\section{Physical Quality of gels}

Observation quality gel peel-off mask preparation was conducted by observing the changes in organoleptic, $\mathrm{pH}$, viscosity, dispersion power, and drying time during the 90 days of storage.

\section{Drying Time Test}

The test was performed by applying the peel off gel mask to the back part of the hand and was observed until the gels dried, and formed easyto-peel-off layer. The test was conducted over period of 90 days of storage.

\section{Microbial Contamination of Gel Mask}

Microbial contamination examing were conducted on the first day and the 90th day of storage. This examination was conducted by using the media Muller Hinton Agar (MHA) as a medium for bacteria and Soburo Dextrosa Agar (SDA) as a medium for fungi.

\section{Antioxidant Activity of gel masks}

Antioxidant activity of the gel maks containing extract were determined by using DPPH method as mentioned earlier on the section of antioxidant activity of extract. Gel masks 
formula F1, F2 and F3 were diluted with water into concentration of $16,8,4,2$, and $1 \mathrm{ppm}$. The absorbance sample were measured bu Uv visible spectrophotometry, and campared with exract and Vitamin $\mathrm{C}$ as standard.

\section{Irritation Test}

Irritation test was conducted on 10 volunteers by using a closed patch test (Patch Test). The peel-off gel mask with the highest concentration of extract were applied on the back part of the right hands of volunteers (measuring $4 \mathrm{~cm} 2$ ) while that without extract was on the left hand. The film were left attached for 10 hours, then the reaction were marked.

\section{Data Analysis}

Data observation were made in the form of a table and then analyzed with a statistical way analysis of variance (ANOVA) with the help of software Statistical Product and Service Solutions (SPSS) version 16.0.

\section{Results and Discussion}

\subsection{Extraction and Phytochemical Screening}

Results obtained by extraction constant viscous extract $538.362 \mathrm{~g}$ giving the yield value of $30.03 \%$. Table 2. Showed the result of Phytochemical Screening. It can be concluded that the extract contain flavonoid, alkaloid and many other biological compound which responsible to its activity as antioidant.

The results of the moisture content determination of green tea leaves extract was $0.83 \%$. This result was in the range of the quality, which should not be more than $10 \%$, in order to avoid microbial growth especially fungus on the extracts.

The results of the water soluble content from green tea leaves extract was $28.5 \%$, while that which ethanol soluble was $56.5 \%$. These results showed that green tea leaves extract is more soluble in ethanol than water.
Table 2. Phytochemical screening of the extract

\begin{tabular}{|c|c|c|}
\hline No & Secondary metabolites & Result \\
\hline \multirow{2}{*}{1.} & Alkaloids: & \\
\hline & a. Reagents Dragendroff & + \\
\hline \multirow[t]{5}{*}{2.} & flavonoids: & \\
\hline & a. Reagents & + \\
\hline & concentrated $\mathrm{HCl}+\mathrm{Mg}$ & \\
\hline & b. $2 \mathrm{~N} \mathrm{H}_{2} \mathrm{SO} 4$ reagent & + \\
\hline & c. Reagents $\mathrm{NaOH} 10 \%$ & + \\
\hline 3. & Polyphenols & + \\
\hline 4. & Tannins & + \\
\hline 5. & Saponin & - \\
\hline \multirow[t]{2}{*}{6.} & Steroids and & + \\
\hline & Triterpenoid & \\
\hline 7. & $\begin{array}{l}\text { Monoterpenes and } \\
\text { Sesquiterpenoids }\end{array}$ & - \\
\hline 8. & Quinone & + \\
\hline
\end{tabular}

\subsection{Antioxidant Activity of Green Tea Leaves Extract}

The results showed that Green tea leaves extract has IC50 value as much as $5.51 \mathrm{ppm}$. IC50 is the concentration that can inhibit 50\% of free radicals. Based on comparison study with vitamin $\mathrm{C}$ as standard, the extract have 0.558 times of the activity compared with vitamin C (IC50 of $3.075 \mathrm{ppm}$ ) as shown in Table 3 and 4. IC50 was later then used as the reference in determining the concentration of the extract to be prepared in gel masks.

Table 3. IC50 Value and \% Inhibition of Green Tea Leaves Extract

\begin{tabular}{cccc}
\hline $\begin{array}{c}\mathrm{C} \\
(\mathrm{ppm})\end{array}$ & $\begin{array}{c}\text { Absorbance } \\
\text { Average }\end{array}$ & $\begin{array}{c}\% \\
\text { Inhibition }\end{array}$ & $\begin{array}{c}\text { IC50 } \\
(\mathrm{ppm})\end{array}$ \\
\hline 0 & 0.832 & - & \\
2 & 0.651 & 21.755 & \\
4 & 0.496 & 40.385 & 5.511 \\
6 & 0.369 & 55.649 & \\
8 & 0.276 & 66.827 & \\
\hline
\end{tabular}

\subsection{Formulation of Peel Off Gel Mask}

Based on the result of optimation process on the gel base formula, to which drying time, F02 was the one which will be used as a basis for further experiment in preparation gel mask due 
to its short drying time. This conclusion also been supported by physical observation on the formula made in optimation process. After 2 weeks of storage of the three formulas were investigated for its elasticity in order to be unbreakable when it is exfoliated (peel-off).

Table 4. IC50 Value and \% Inhibition of Vitamin C

\begin{tabular}{cccc}
\hline $\begin{array}{c}\mathrm{C} \\
(\mathrm{ppm})\end{array}$ & $\begin{array}{c}\text { Absorbance } \\
\text { Average }\end{array}$ & $\begin{array}{c}\% \\
\text { Inhibition }\end{array}$ & $\begin{array}{c}\text { IC50 } \\
(\mathrm{ppm})\end{array}$ \\
\hline 0 & 0.807 & - & \\
0.25 & 0.758 & 6.071 & \\
1 & 0.657 & 18.587 & 3.075 \\
2 & 0.539 & 33.209 & \\
4 & 0.289 & 64.188 & \\
$\mathrm{C}$ & concentration of sample &
\end{tabular}

Further formulations of antioxidant green tea leaves extract gel mask were performed by using F0 base with addition of the extract at concentration of $0.0005 ; 0.0015$; and $0.0025 \%$.

\subsection{Physical observation results of the gel masks}

Formula of gel mask with various concentrations of green tea leaf extract showed the consistency, smell, and color which unchanged for 90 days of storage, indicating that no decomposition of materials or excipient of gel mask interact and causing changes in consistency, smell, and color.

\section{$3.5 \mathrm{pH}$ of gel masks}

The study were performed to investigate the effect of different concentration of extract on $\mathrm{pH}$ of gel formulation. Formula gel masks with various concentration of green tea extract tend to have acidic $\mathrm{pH}$ which between 5-5.5, that probaly due to the green tea leaves extract which has a $\mathrm{pH}$ of 4.4. During the storage period, the $\mathrm{pH}$ of each formula gel mask changed but still in the area of $\mathrm{pH}$ for topical preparation (Figure 2). The change in $\mathrm{pH}$ can be due to chemical reaction in the gel or by the effect of extract itself which contain many biochemical constituent 7,8,9.

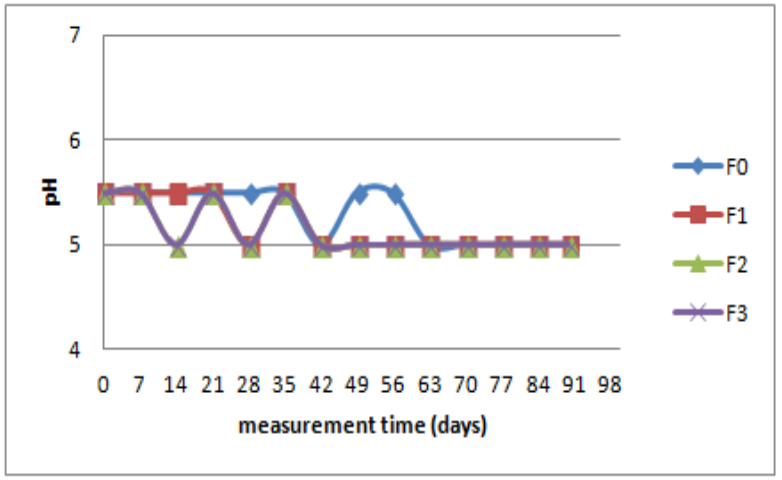

Figure 2. Changes in the $\mathrm{pH}$ curve Gel Mask with different concentration of Green Tea Leaves Extract for 90 Days of Storage

\subsection{Viscosity of gel masks}

The study on viscosity of all gel mask formula were conducted to evaluate the effect of different concentration of extract on viscosity of gel formulations. The results showed that the viscosity of gel containing different concentration of extract did not significantly change during 90 days of storage (Figure 3). Accordingly, viscosity of the gel were all in the range of required viscosity 10,11. The exception was found on gel formula without the addition of extract to which it revealed the increase after 28 days of storage. This phenomena can be explained by the possibility of water evaporation from the gels.

\subsection{Drying Time}

Based on the result of drying time test during optimation, gel formulation with propylen glycol (F02) was that with short drying time. Further investigation were conducted using propylen glycol as humecta, with different concentration of extract as active ingredient.

The results of investigation on drying time of gel mask showed that the drying time were in the range of drying mask products in the market, which lied between 10-20 minutes 12 . The drying time between the three of the formula was not significantly different due to small difference of extract concentration as active substance in the formula (Figure 4). 


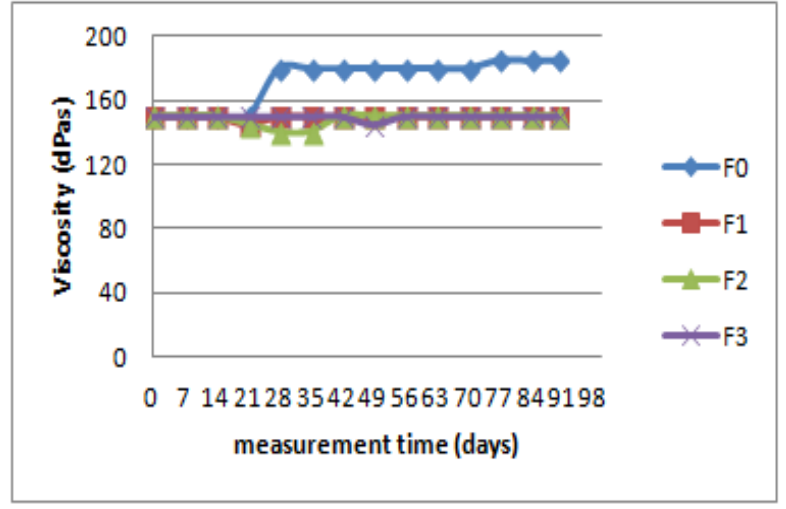

Figure 3. Changes in Viscosity Curve Gel Mask with Green Tea Leaves Extract for 90 Days of Storage

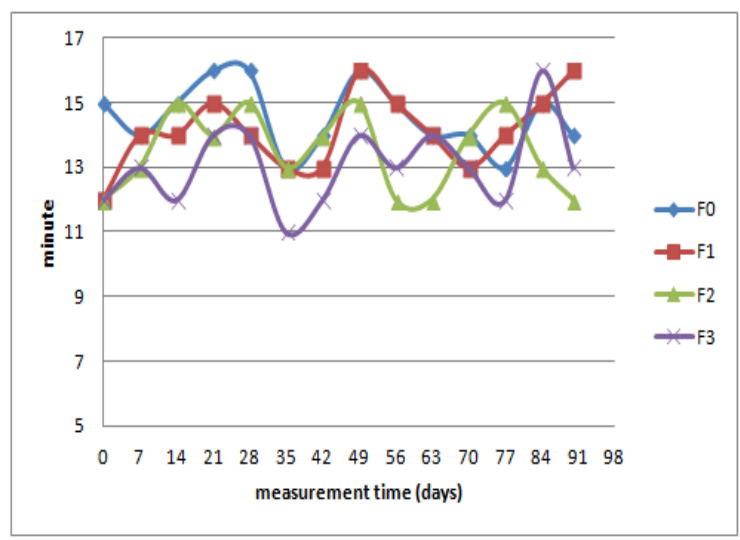

Figure 4. Drying Time of gel masks with Green Tea leaves extract during 90 days of storage

\subsection{Dispersion power of Gel masks}

The purpose of dispersion power test was to determine the ability of gel to easily being spread on the surface of the skin without significant pressure. From the data, it can be concluded that the dispersion power of all gel masks formulation were in the range of $5-7 \mathrm{~cm}$ and revealed no significant difference during 90 days of storage. The test results of the dispersion power can be seen in Figure 5 . Dispersion power were highly influenced by gel strength thus the type of gel base were very influencing13, 14, 15.

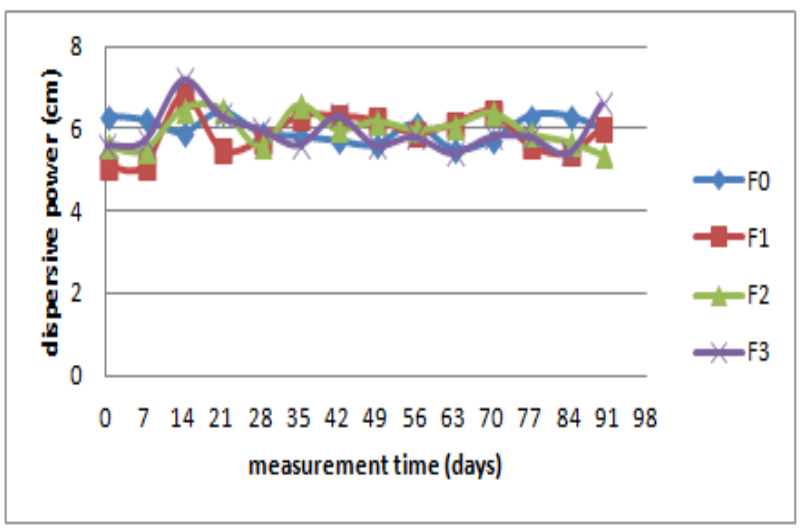

Figure 5. Curve Changes in Dispersion Power with Green Tea Extract Leaves for 90 Days of Storage

\subsection{Determination of Antioxidant activity of gel masks}

With regard to the IC50 values, a compound is defined to be the strong antioxidant when the IC50 value is less than 50ppm. Strong antioxidant has the IC50 value of 50-100ppm, moderate antioxidant has IC50 value between 100-150 ppm IC50, and is is undermined when IC50 value is $150-200 \mathrm{ppm}$ or over 200. Antioxidant activity of three gel masks formulas showed the IC50 below 20 which revealed strong antioxidant activity. Compared to the IC50 of extract (found to be $5.511 \mathrm{ppm}$ ) the antioxidant activity of extract were decreased which due to dilution effect of excipients. Accordingly, an increase in IC50 value, which revealed the decrease in antioxidant activity can be seen after 90 days of storage (Figure 6). It is noticable that the decrease was much lower when the extract was used at higher concentration (Figure 6). Decrease in antioxidant activity was may due to the influence of the interaction between the extract with excipient of gel mask used in the formula16. Mechanism of reaction between the extract and excipients need to be further investigated. Somehow, this problem can be overcomed by increasing the concentration of the extract as active substance. 


\subsection{Microbial contamination}

Investigation on microbial contamination was conducted as the base of preparation were water based hidrogel polymer which higly in risk to be contaminated by microbial growth, therefore the microbial testing is obligatory for those formulations. Based on the results, microbial contamination carried out on the first day of preparations were zero, and so did after day 90 of storage. It can be concluded that antimicrobial used as the preservative in the formulation is effective either to maintain the microbial growth or to preserve the formulations.

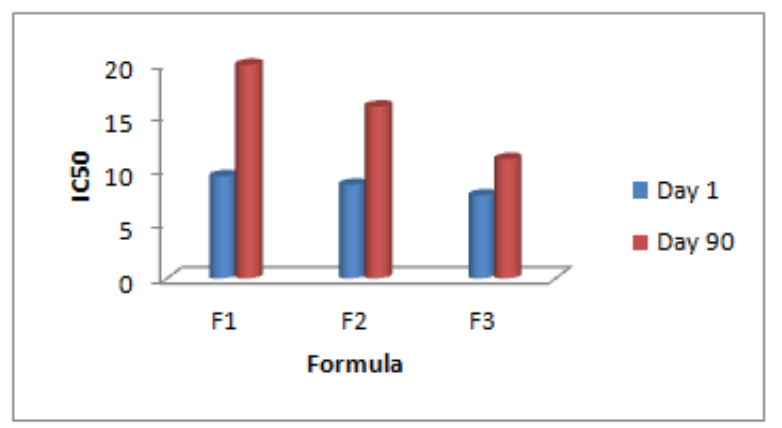

Figure 6. Results of Measurement of Antioxidant Activity Preparations Gel Mask with Green Tea Leaf Extract on Day 1and Day 90

$\mathrm{F} 1=$ gel mask with tea leaves extract $1 \times$ IC50

$\mathrm{F} 2=$ gel mask with tea leaves extract $3 \times$ IC50

$\mathrm{F} 3=$ gel mask with tea leaves extract $5 \times$ IC50

\subsection{Skin irritation study}

Gel masks with or without addition of tea leaves extract did not cause any irritation to the 20 volunteers, both primary and secondary irritation. The results marked as no occurrence of burnt, redness, and swelling in volunteer skin, and can be concluded that either the material or extract used in gel masks is safe to be used.

\section{Conclusion}

The antioxidant activity of green tea leaves extract was 0.558 times compared with vitamin
$\mathrm{C}$ as vitamin $\mathrm{C}$ has IC50 of $3.075 \mathrm{ppm}$ while that of green tea leaves extract was IC50 5.511 ppm. Formula of antioxidant gel mask used green tea leaf extract concentration as much as: 1x IC50(F1); 2x IC 50 (F2) and 3 x IC 50 (F3). All formulation were generally stable including $\mathrm{pH}$, drying time, viscosity and dispersion power after 90 days of storage. Antioxidant activity of gel masks were defined as the strong antioxidant due to its IC50 which less than 50 ppm.

\section{Conflict Of Interest}

None

\section{References}

1. Yaar, M \& Gilchrest, BA. 2007. Photoaging: Mechanism, Prevention and Therapy. British Journal of Dermatology, Vol. 157, pp. 874-7.

2. Winarsi, H. 2007. Antioksidan Alami \& Radikal Bebas. Yogyakarta. Penerbit Kanisius. Hal 15, 20, Youngson, Robert.

3. Tuminah, S., 2004. Teh [Camellia sinensis O.K. var. Assamica (Mast)] as potential source of antioxidant. Cermin Dunia Kedokteran. Ministry of health, Republic Indonesia

4. Mitsui, T. (1997). New cosmetic science: Elsevier

5. Harry,R.G.1973.

Harry's Cosneticology: The Principle And Practice Of Modern Cosmetic . vol. I . Great Britain 95.

6. Shai, A., Maibach, H. I., \& Baran, R. (2009). Handbook of Cosmetic Skin Care (Second Edition ed.). USA: Informa UK.

7. Picone, Carolina Siqueira Franco. Rosiane Lopes Cunha. 2011. Innfluence of pH on Formation and Properties of Gellan Gels. J. Carbohydrate Polymers. 84. 662-668 
8. Funami, T., Hiroe, M., Noda, S., Asai, I., Ikeda, S., \& Nishinarib, K. (2007). Influence of molecular structure imaged with atomic force microscopy on the rheological behavior of carrageenan aqueous systems in the presence or absence of cations. Food Hydrocolloids, 21, 617-629.

9. Maibach, Howard I. Andre O Barel. Marc Paye. (2009). Handbook of cosmetic science and technology. New York: Informa Healthcare

10. Garg, A., Aggarwal, D., Garg, S., \& Sigla, A. K. (2002). Spreading of Semisolid Formulation. USA: Pharmaceutical Technology.

11. Black, B. E. T. White. (1977). The Effect of Aeration on the Viscosity of Molasses. Brisbane River: Chemical Engineering Department, University of Queensland.

12. Rees, D. A. (1969). Advances in Carbohydrate Chemistry and Biochemistry. In
M. L. Wolfrom, Tipson, R.S., Horton, D (Ed.), Structure, conformation, and mechanism in the formation of polysaccharide gels and networks. (Vol. 24). London: Academic Press.

13. MR, Mangione Giacomazza., D. Bulone, D. Martorana, V. San Biago, VL. (2003). Thermoreversible gelation of kCarrageenan: relation between conformational transition and aggregation. Biophysical Chemistry, 104, 95-105.

14. Auras., Jasim Ahmed, Rafae. (2011). Effect of acid hydrolysis on rheological and thermal characteristics of lentil starch slurry. Food Science and Technology, 44.

15. Singla, Anil K. Alka Garg. Deepika Aggarwal. Sanjay Garg. (2002). Spreading of Semisolid Formulations An Update. Pharmaceut. Technol.

16. Rowe, R. C., Sheskey, P. J., \& Weller, P. J. (2009). Handbook of Pharmaceutical Excipients (Sixth Edition ed.). London: Pharmaceutical Press. 